Ensino, Saúde e Ambiente-V5 (2), pp. $79-89$, ago. 2012

\title{
ENSINO DE CIÊNCIAS NAS SÉRIES INICIAS: ADAPTAÇÕES A PARTIR DA LITERATURA INFANTIL
}

\section{THEACH OF SCIENCE OF THE LOWER GRADES: ADAPTATIONS FROM CHILDHOOD LITERATURE}

\author{
Tatiana Pereira da Silva ${ }^{1}$, Luís Paulo de Carvalho Piassi ${ }^{2}$ \\ ${ }^{1}$ Universidade de São Paulo/Escola de Artes, Ciências e Humanidades, tatianasilva@usp.br \\ ${ }^{2}$ Universidade de São Paulo/Escola de Artes, Ciências e Humanidades, lppiassi@usp.br
}

\section{RESUMO}

Este trabalho apresenta uma análise da utilização de livros de literatura infantil para a produção de roteiros de teatro de fantoches. Foram analisadas diversas obras infantis com o objetivo de verificar quais as condições necessárias, em sua estrutura narrativa, para adaptações de forma adequada. Além disso, as possíveis conexões com o ensino de ciências e os temas que podem ser aplicados nas séries iniciais do ensino fundamental.

Palavras-chave: teatro de fantoches, ensino de ciências, literatura infantil.

\section{ABSTRACT}

This paper presents an analysis of the use of books in children's literature to produce scripts for Puppet Theater. We analyzed several works for children in order to determine what conditions are necessary, in its narrative structure to adapt appropriately. Furthermore, the possible connections with the teaching of science and the issues that can be applied in the early grades of elementary school.

Key words: puppets show, children's literature, science education.

\section{INTRODUÇÃO}

A importância do ensino de ciências para os alunos do ensino fundamental em fase inicial de alfabetização se faz necessária quando associamos às possibilidades de desenvolvimento no aprendizado que a ciência traz ao indivíduo. Como resume Charpak (1996), o ensino científico é uma forma de construir na criança, considerando toda sua globalidade, o saber, o saber-fazer e o saber ser. Neste caminho, o ensino de ciências quando ampliado às séries iniciais, atua diretamente nas ações de curiosidade e descobertas, incluindo a imaginação e a criatividade muito frequentemente ativas no início da idade escolar. Logo, transforma expectativas particulares vindas dessas ações em tentativas e reflexões cada vez mais consolidadas e progressivamente construídas. Busca-se, portanto, um contexto em que a criança seja capaz de desenvolver competências em relação ao conceitual, numa dimensão possível de obter significados construtivos de seu próprio conhecimento. E, certamente, envolver atitudes comuns na 
Ensino, Saúde e Ambiente - V5 (2), pp.79-89, ago. 2012

apresentação dos conteúdos, ampliando as possibilidades de contextualização dos valores morais e do desenvolvimento da cidadania. Ainda nessas considerações, acrescentam-se os aspectos ativos do aluno na organização sistemática e na tomada de decisões proporcionadas em atividades científicas, e por fim, de modo englobado, conseguir estabelecer relações entre todas essas situações.

Uma vez que as práticas de ler, escrever e raciocinar matematicamente são amplamente ensinadas nas séries iniciais, complementar o ensino utilizando as ciências naturais, não se trata de abandonar tais conteúdos, mas incorporá-los à proposta do ensino de ciências como método de reforço e sentido. Junto ao aprendizado cientifico o aluno consegue então ampliar as possibilidades de compreender e praticar todos esses conteúdos. Em relação à alfabetização cientifica nas séries iniciais Delizoicov \& Lorenzeti (2001), afirmam que junto à escola, espaços e meios que diferenciem do modelo tradicional de sala de aula podem auxiliar na efetivação desse processo. Nesse sentido, os mais variados mecanismos podem ser citados, como a literatura, os vídeos, músicas, museus, inclusive o teatro de fantoches.

O mundo infantil é rodeado por uma série de relações criadas pelas crianças no sentido de sustentar situações imaginárias, dando vida aos brinquedos e relacionando-se e comunicando-se igualmente com o mundo inanimado. Para Amaral (1991), o teatro de fantoches é capaz de estabelecer relação direta com esse pensamento animista infantil, logo, tem condições para satisfazer os anseios de transformação que a criança tem de tornar real os seus sonhos de poder. Uma vez que o teatro de fantoches é um recurso estimulante que pode funcionar como ponto de partida para a disposição de múltiplas atividades, pretende-se analisar a literatura infantil como instrumento para a produção de enredos para peças de teatro de fantoches. Tendo em vista essa possibilidade, passa-se a verificar as relações com o ensino das Ciências por meio dos conteúdos possíveis de serem destacados e aplicados em sala de aula.

\section{PRODUZINDO PEÇAS A PARTIR DA LITERATURA INFANTIL}

Não é comum encontrar roteiros para peças de teatro de fantoches na literatura, devido a isso utilizamos como base para a produção de enredos as obras literárias infantis. Livros de literatura infantil são abundantes, apresentam uma quantidade de histórias variadas e com frequência fazem parte do cotidiano escolar, 
permitindo escolher um roteiro adequado aos conteúdos que se pretende trabalhar. Para a escolha de um livro considerado adequado, foram analisados aproximadamente 50 livros de literatura de infantil de editoras e autores diferentes presentes nas bibliotecas escolares. Apesar da quantidade de livros infantis com histórias variadas, nem todos são viáveis para a realização de tal tarefa, algumas características básicas na estrutura da narrativa facilitam a adaptação para que contemple a finalidade da apresentação e contabilize para a compreensão do espectador.

\section{a) Critérios quanto à estrutura da narrativa}

Existem muitos objetos de constituição da obra que caracterizam e definem a estrutura de uma narrativa em um livro de literatura infantil. Aqui, destacaremos apenas os elementos mais fundamentais para compor uma adaptação adequada no uso em teatro de fantoches para crianças.

As histórias de literatura infantil são normalmente compostas por diferentes fases do estado de equilíbrio, ou seja, é comum que, a história tenha uma situação inicial, em harmonia ou equilíbrio. Ao longo da história, há possibilidade de rompimento desse estado, havendo um problema. E por fim, todo o estado inicial é recuperado com a solução ou não do problema, mas, de qualquer forma, retorna a situação de equilíbrio, algumas vezes por meio de uma conclusão alternativa. Esse tipo de estrutura é definida por Faria (2008) como narrativa-padrão, estando sempre organizados em três elementos de momento, principiando por uma situação inicial, o desenvolvimento (que, geralmente, inclui a busca por solução de um conflito) e o desenlace. Um exemplo de livro de literatura infantil que contém esse tipo de estrutura é a história A pena de Katja Reider (2002). No estado inicial, dois animais, a galinha e a toupeira, são amigas inseparáveis. Esse estado de equilíbrio é quebrado no momento que a galinha decide ir embora (Fig.1). 


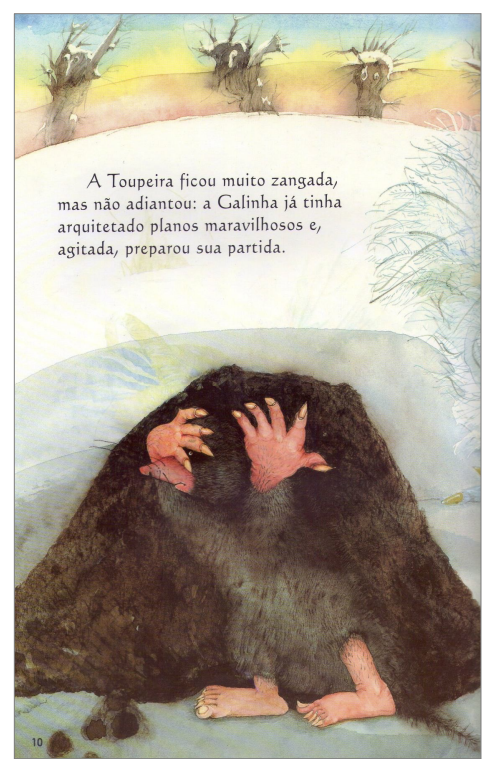

Fig. 1. Cena em que a galinha está de partida e deixa a amiga toupeira desapontada.

Durante o desenvolvimento da história é comum que os personagens tentem encontrar soluções para o problema gerado, assim, nesta história a toupeira utiliza a pena deixada pela galinha como objeto de distração pelo abandono da amiga. No desfecho, volta-se ao estado inicial, pois a galinha decide retornar para a toca da toupeira (Fig. 2). Neste caso o rompimento do equilíbrio estabelecido logo após o inicio da história é rearranjado pela solução do problema, obtém-se uma finalização positiva para ambos os personagens. 
Ensino, Saúde e Ambiente-V5 (2), pp. $79-89$, ago. 2012

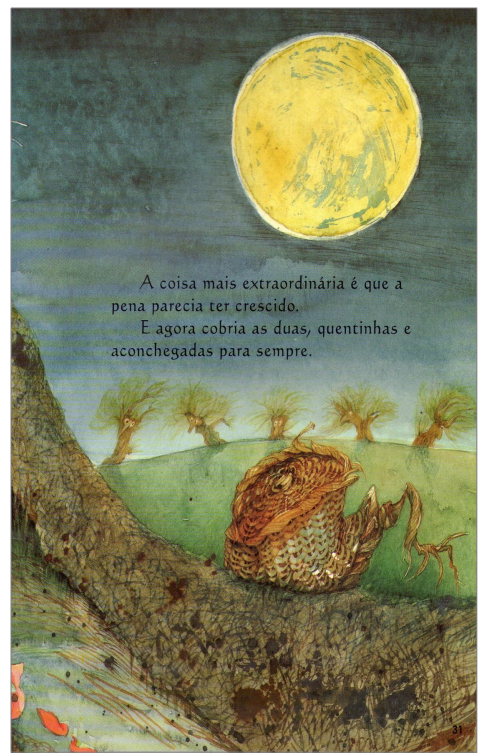

Fig. 2. Fim da história e solução do problema.

Outro exemplo é a história Onde Lua perdeu o sorriso? de Miriam Sánchez (2006). Este enredo já inicia com um problema, o desaparecimento do sorriso da menina Lua, que nenhum personagem sabe como desapareceu e nem onde encontrar. Por todo o desenvolvimento, os demais personagens tentam encontrá-lo, pois, só assim conseguirão resolver o problema. Somente o último personagem é capaz de oferecer uma sugestão para encontrar e devolver o sorriso a menina (Fig.3), e completar uma solução para o desenlace.

As duas histórias apontadas acima mostram a sequência existente que leva ao esquema: equilíbrio - rompimento do equilíbrio - desenvolvimento (busca da solução) - resolução. 


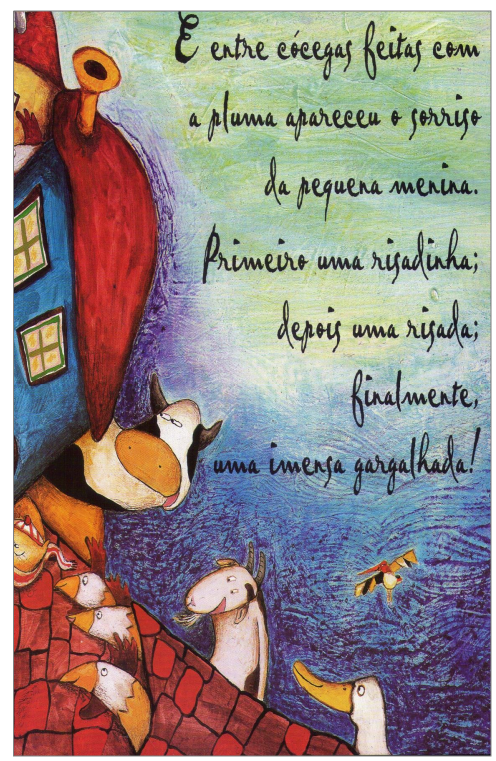

Fig. 3. Última página do livro Onde Lua perdeu seu sorriso?

Esses elementos quando articulados aos bonecos de fantoches e ao cenário constroem mais facilmente uma sequência lógica para a compreensão da história pelas crianças. Como o material de teatro de fantoches possibilita um nível limitado de expressões, com este tipo de trajetória, o enredo consegue delimitar mais facilmente os acontecimentos da história.

Dentro da perspectiva dessa estrutura estão acoplados outros elementos fundamentais para viabilizar a adaptação para uma peça de teatro de fantoches. Por exemplo, a presença de falas dos personagens ou do narrador no lugar do mesmo. Esse tipo de característica em uma história é importante para a adaptação, pois possibilita maior flexibilidade entre o enredo, o personagem, e o fantoche como material, já que este último tem um nível de articulação e expressões limitado, em que o maior número de falas contribui para a compreensão da história, podendo ser contada somente pela ação e fala dos personagens sem a necessidade de um narrador. Apesar de ser uma adaptação, quando a história já contém algumas falas evita-se que sejam produzidas maiores integrações e modifique o sentido da história. Outro aspecto que deve ser observado é o espaço em que a história ocorre, é necessário que o enredo possibilite a adaptação para um espaço limitado de ocorrência, pois o cenário do teatro de fantoches normalmente é pequeno e a decoração reproduz apenas um determinado ambiente, de forma fixa. E, por último, o tamanho da história também deve ser observado. Quando o 
livro de literatura infantil escolhido apresenta uma história longa é necessário observar quanto a possibilidade de reduzi-la otimizando ao tempo de aula e adequando a idade dos alunos.

Em alguns casos, o livro de literatura infantil não apresenta narrativa com esse tipo de estrutura. A narrativa destaca um gênero descritivo, em que, basicamente, não há tensão inicial com resolução de um problema no meio ou no fim da história. Aponta apenas descrição de características e atividades comuns e diárias de um determinado personagem, o problema inicial não é uma tensão ou momento de perigo e no fim não há necessidade de resolução. Como exemplo podemos apontar a história de A esquisita aranha Rita de Lúcia Reis (2008), que inicia apresentando a personagem pelo seu nome e nas páginas seguintes descreve o que outros personagens acham de Rita, as atividades que ela gosta de fazer sozinha e com seus amigos (Fig. 4).

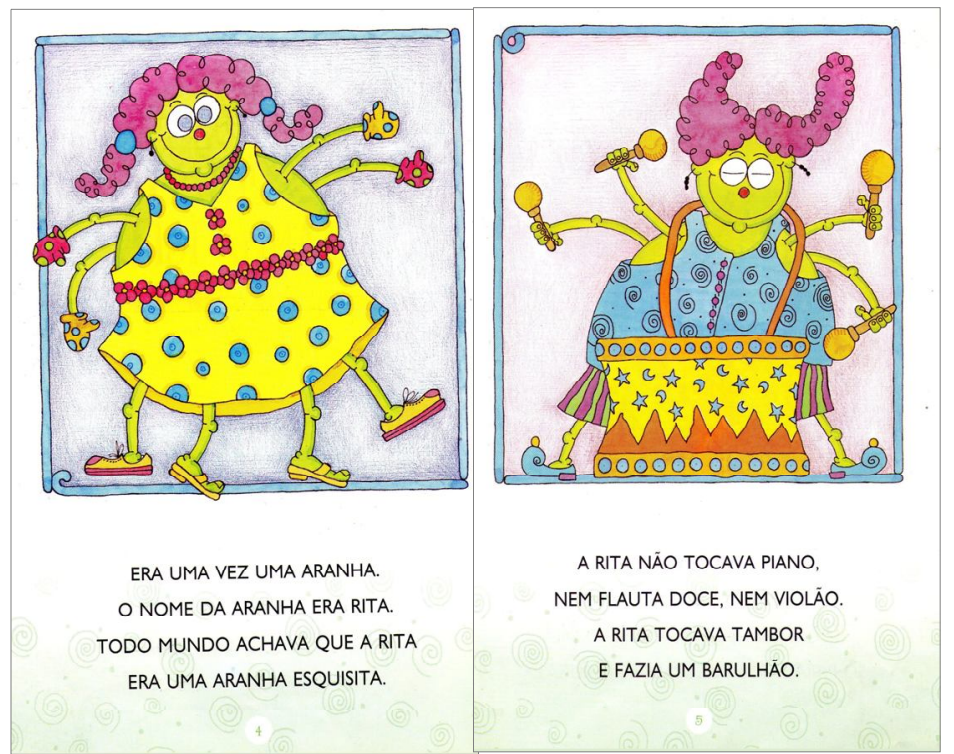

Fig. 4. Primeira e segunda página do livro A esquisita aranha Rita, não apresenta tensão inicial, só relata as qualidades e os defeitos da personagem.

Por fim, o texto da história conclui dizendo que tudo o que foi descrito era o que fazia a aranha feliz, apresentando apenas momentos específicos da vida cotidiana desse personagem e o caracterizando em todo o enredo.

Além desse aspecto, a história é narrada do início ao fim. A aranha e os outros personagens não se comunicam entre si, nem diretamente com o leitor, não apresentando falas. Quando o livro de literatura apresenta a narração do tipo descritiva, 
para ser transportado a uma peça de teatro de fantoches necessitaria, em primeiro lugar de um narrador ou que fossem criadas falas para estabelecer compreensão do enredo por completo.

Os apontamentos supracitados facilitam e viabilizam, em termos práticos, a adaptação da história de um livro de literatura infantil para o enredo de uma peça de teatro de fantoches.

\section{b) Critérios quanto ao conteúdo}

Elaboramos um roteiro de peça de teatro de fantoches baseado no livro de literatura infantil "Enquanto a mamãe galinha não estava" da editora Callis, Coleção Tan Tan. Nesta história a mamãe galinha sai para ir às compras e deixa seus ovos sozinhos no ninho por um determinado período. Durante esse passeio surgem alguns personagens que aprontam travessuras com os ovos. Em primeiro lugar, duas crianças curiosas e, em seguida, outros animais, o desajeitado papai galo, a tia pata atrapalhada e até o perigoso lobo mau fazem parte do episódio enquanto a dona do ninho não retorna (YEONG-SO e BYEONG-HO, 2006). Esta obra apresenta o modelo de constituição como o apontado acima, com equilíbrio, desequilíbrio, resolução e equilíbrio, sucessivamente.

Essa adaptação da obra de literatura infantil foi realizada a fim apresentar uma forma de como evidenciar os conteúdos a serem trabalhados, neste caso, os que se referem às Ciências, a viabilidade de produção e aplicação escolar, bem como a delimitação de tempo e espaço, e a influência ativa entre a história e a criança.

Com o propósito de elaborar uma peça de teatro de fantoches alguns critérios em relação ao conteúdo da história foram estabelecidos antes da seleção desta obra, sendo eles:

- $\quad$ O envolvimento de animais como personagens principais;

- Enredo com situações semelhantes às relações e condições de sobrevivência de animais reais.

Delimitamos esses critérios, pois tais características aparecem como tema comum nas obras literárias infantis, ocupando considerável espaço no cotidiano das crianças por meio de jogos, desenhos animados etc., que comumente fazem parte do universo de criação imaginária da criança. Além disso, a antropomorfização oferece a 
Ensino, Saúde e Ambiente - V5 (2), pp.79-89, ago. 2012

oportunidade de aproximação da criança com a obra e identificação com o personagem, garantindo maior nível de afinidade (ZANCANI, 2006), logo, ajusta-se ao contexto cultural do aluno podendo aumentar o interesse. Além disso, a obra escolhida contempla, de forma justa, as características da estrutura da narrativa necessárias para a adaptação de forma harmoniosa, como discutido anteriormente.

A partir da adaptação do livro de literatura infantil, a história se desenvolve com número menor de personagens, reduzindo à duas crianças e três animais, o que proporcionou incorporarmos competências cognitivas, afetivas, sociais e culturais, por meio das novas relações de interação e aspectos conceituais. Os animais apresentados na história são comuns em livros infantis, como galo, galinha e lobo. No novo enredo, esses e os outros personagens, durante o desenrolar da história, irão passar por variadas situações com o mesmo propósito, de manter seguros os ovos da galinha.

\section{c) Quanto aos conteúdos de ciências}

Esta pesquisa tem direcionamento que propõe unir uma história de teatro de fantoches aos conteúdos de ciências que podem ser abordados nas séries iniciais, como

já discutido anteriormente. À medida que o novo roteiro da peça de teatro de fantoches tomou forma alguns conceitos científicos que já estavam presentes na história original ganharam destaque e outros surgiram convenientemente. Assim, em cada detalhe da nova história alguns conceitos das diversas áreas dos saber sobressaem trazendo a possibilidade de trabalho em sala de aula para complementar o processo de ensinoaprendizagem. Dentre eles, no que se refere às Ciências Naturais, foram escolhidos:

\section{- Conceitos Ecológicos}

Destacando o comportamento animal em relação aos conceitos de presa e predador e aspectos alimentares dos animais pelos princípios da cadeia alimentar.

\section{- Conceitos Zoológicos}

Apresentação de características distintas dos animais, destacando as noções elementares da classificação dos seres vivos.

Os conceitos ecológicos foram escolhidos para serem tratados, pois são assuntos muito comuns nas obras de literatura infantil, que em sua maioria tem animais como personagens, e um dos mais evidentes no que se refere as relações existentes entre os animais. Junto a isso, são temas que na maioria dos casos geram conclusões 
Ensino, Saúde e Ambiente -VV5 (2), pp.79-89, ago. 2012

incorretas pelas crianças em idade escolar pois é comum que atribuam valores morais, até mesmo pelos exemplos nos próprios livros de literatura infantil e outros objetos do cotidiano extraescolar, como desenhos e filmes animados. Os conceitos zoológicos que se referem aos seres vivos foram escolhidos como forma de principiar um dos conteúdos de ciências naturais para o primeiro ciclo dos Parâmetros Curriculares Nacionais (BRASIL, 1997). Uma vez que os conteúdos sugeridos pelos PCN's envolvem noções do ambiente e colocam como um dos tópicos as interações entre os componentes do meio, incluindo os seres vivos, concentramos o tema que será discutido durante a atividade desta pesquisa em uma forma de tornar perceptível pelas crianças alguns fundamentos das classificações dos seres vivos, lhes mostrando a diferença entre os animais. Acreditamos ser esse um assunto importante antes que os alunos tratem, propriamente, da investigação das interações entre os seres vivos.

Além dos assuntos de Ciências escolhidos, outros diversos desta mesma área poderiam ser tratados, bem como de outras áreas do ensino como Português e Matemática (noções de quantidade) e outros temas ligados às relações e desempenho de papéis sociais também poderiam ser tratados, pois fazem parte do contexto geral da história.

\section{CONCLUSÃO}

Com a realização desse trabalho foi possível perceber a dificuldade em encontrar e produzir uma peça de teatro de fantoches, apesar disso, é imediata a percepção do quanto esse tipo de atividade desperta o interesse de participação do aluno em sala de aula, além de funcionar como um ponto de partida para o trabalho com uma variedade imensa de assuntos que podem ser tratados em aula, podendo abordar várias disciplinas e dar margem ao desenvolvimento da interdisciplinaridade. Utilizando formas adequadas de adaptação é possível compreender mais facilmente os mecanismos para a aplicação em diversas situações, de acordo aos objetivos, essencialmente os relacionados às atividades em sala de aula.

A adaptação do livro de literatura infantil configurou uma possibilidade de aumentar o nível de interação entre as crianças e os personagens da história, por ser este um material comumente utilizado em sala de aula, proporcionou maior nível de interesse e identificação, além disso, favoreceu a possibilidade de aplicação em sala de 
Ensino, Saúde e Ambiente-V5 (2), pp. $79-89$, ago. 2012

aula por ter curto tempo de apresentação e se encaixar no tempo de aula oferecido aos alunos das séries iniciais do ensino fundamental.

\section{REFERÊNCIAS}

AMARAL, A. M. Teatro de formas animadas: máscaras, bonecos, objetos. São Paulo: Edusp, 1991.

BRASIL, Secretaria da Educação Fundamental. Parâmetros Curriculares Nacionais. Ciências Naturais / Secretaria de Educação Fundamental. Brasília: MEC/SEF, 1997.

CHARPAK, G. As ciências na escola primária: uma proposta de ação. Sintra/ Portugal: Inquérito, 1996.

DELIZOICOV, D., LORENZETI, L. Alfabetização científica no contexto das séries iniciais, jun. 2001. Ensaio Pesquisa em Educação em Ciências. Belo Horizonte, Volume 3. Número 1, 2001. Disponível em:

http://www.fae.ufmg.br/ensaio/v3_n1/leonir.PDF>. Acesso em: 19 jul. 2010.

FARIA, M. A. Como usar a literatura infantil na sala de aula. $4^{\mathrm{a}}$ ed. $2^{\mathrm{a}}$ reimpressão. São Paulo: Contexto, 2008.

REIDER, K. A pena. São Paulo: Brinque-Book, 2002.

REIS, L. A esquisita aranha Rita. $2^{\text {a} e d . ~ S a ̃ o ~ P a u l o: ~ P a u l i n a s, ~} 2008$.

SÁNCHEZ, M. Onde Lua perdeu o sorriso? São Paulo: Callis, 2006.

YEONG-SO, Y.; BYEONG-HO, H. Enquanto a mamãe galinha não estava. São Paulo:

Callis, 2006.

ZANCANI, C. A visão premiada da infância: a legitimação do livro infantil In: Aguiar, V. T. E Martha, A. A. P. Territórios da leitura. Da literatura aos leitores. Assis: Cultura Acadêmica, 2006. 